\title{
EFFECTS OF PREVENTIVE MENTAL HEALTH IN SECONDARY SCHOOLS
}

\author{
Bror Just Andersen
}

\begin{abstract}
In the research project in my doctoral thesis I wanted to test the effects of a short preventive mental health program in secondary school. In 2007 there was established a longitudinal study with a test group and a control group $(\mathrm{N}=1671)$, built upon Solomon's design. Data was collected through questionnaires prior to intervention and at 1, 6, 12, and 24 months after the intervention. Effect sizes on the various indices are estimated in terms of (a) differences in improvements of total percentage scores and (b) Cohen's d. From to to t1, t2 and t 3 the intervention group showed significantly greater progress in 6 out of 7 knowledge indexes, and 12 months after the intervention we found significant effects in reduction of mental health problems.
\end{abstract}

\section{Keywords}

prevention, mental health, secondary school, research, intervention

\section{Introduction - Background}

Clinical studies have shown that depression in adolescents is under-diagnosed and that too few receive treatment. In 2000 it was found in the U.S., that only $20 \%$ of severely depressed youth receive treatment. In the same study it was also found a high recidivism, and by the age of 24 years, many had developed other mental health problems and substance abuse problems in addition to depression, especially alcohol and drug abuse (Lewinsohn, Rhode, Seeley, Klein, \& Gotlib, 2000). Studies in Norway have shown that between 15 and $20 \%$ of children have mental health problems that go beyond their ability to function, and between 5 and $7 \%$ the problems is so severe that they need professional treatment (NDH 2000, NOKC 2004).

Reports and research indicate that these figures could be reduced by increasing knowledge through universal prevention, including such as behavioral changes and that knowledge increase could reduce the duration of untreated problems. For such 
a purpose, schools seem to be a suitable arena. "VIP" (the Norwegian abbreviation of Guidance and information about mental health), that was started in 2000 on the initiative of the user council at Blakstad hospital in 1999 (VV HT 2016). The background for initiating the intervention was that users felt that if they had gained knowledge about mental health problems, disorders and where they could seek help before the problems started, they'd probably tackled the problems in a better way and sought help set earlier. The intervention is short (approximately five school hours in two weeks) focusing, first and foremost, on reducing incidence of mental health problems through building knowledge about mental health among the youth. Secondly, it contributes to a closer relationship between primary everyday venues and primary service for young people, across professions, sectors and services.

In the school year 2007/08, VIP was conducted at 128 schools in 15 out of 19 counties. The program is founded on dialogue, empowerment and salutogenesis, and has elements of both prevention and promotion. In May 2005, the intervention was included in The Norwegian Directorate of Health cooperative project: "Mental Health in Schools" (NDH 2013).

Manuals for implementation are prepared for all parts of the project, and it requires no special prior knowledge of the teacher (more about the manuals, see the interventions website (VV HT 2016)).

The implementation of the project is interdisciplinary and cross-sectional. It involves the coordinator of mental health in the community, the school administration and teachers, school nurse and specialist metal health services. The intervention differs from many types of school-based prevention activities through the focus on knowledge-dialogue based presentation and by the degree of involvement of the local support agencies (VV HT 2016).

\section{Previous Effect Evaluation of Psycho Educational Interventions}

In international surveys, including both longitudinal studies (Spence, Sheffield, \& Donovan, 2005) and reviews of universal preventive interventions in depression (Cuijpers, van Straten, Smit, Mihalopoulos, \& Beekman, 2008; Cuijpers, Munoz, Clarke, \& Lewinsohn, 2009; Durlak, \& Wells, 1997; Horowitz, 2006; Merry, McDowell, Hetrick, Bir, $\&$ Muller, 2009) and mental health, the relevant comparable effect sizes vary, where such are reported, between 0.26 to 0.57 (Lipsey, \& Wilson, 1993; Merry et al. 2009; Weist, \& Albus, 2004; Weisz, Sandler, Durlak, \& Anton, 2005). The dependent variables in the study encompass changing, self-perception, behavior, coping, problem solving, school and mental health climate, and referrals. Several review articles conclude positively about prevention and early intervention for anxiety and depression (Gillham, Shatte, \& Freres, 2000; Greenberg, Domitrovich, \& Bumbarger, 2001; Jané-Llopis, 2005, Tennant, Goens, Barlow, Day, \& Stewart-Brown, 2007). When the interventions are universal, these generally accomplish a slightly weaker effect. On the other hand, they reach a much 
larger number of people and therefore can be justified with a relatively lower power. Thus, variations in relation to generalized effect are larger, the orientation remains mainly significant and positive (Arnarson, \& Craighead, 2009; Aune, \& Stiles, 2009; Farrington, \& Ttofi, 2010; Merry, \& Spence, 2007; Neil, \& Christensen, 2009).

There are a limited number of studies that have measurements at six and twelve months (Gladstone, \& Beardslee, 2009; Lipsey, \& Wilson, 1993). The studies that have a longitudinal design have made findings that are consistent with the findings made in my research (Andersen, \& Nord, 2010a; Andersen, Johansen, \& Nord, 2010b; Andersen, 2011; Andersen, Johansen, \& Nord, 2012, available only in Norwegian). Some of the studies are of limited interest in our context, since they are selective and not universal (Neil, \& Christensen, 2009; Merry, \& Spence, 2007; Arnarson, \& Craighead, 2009; Aune, \& Stiles, 2009). These include programs that were aimed at reducing anxiety in anxiety patients.

\section{The Effect Evaluation of VIP}

The undersigned conducted from 2007-2010 an effect evaluation of VIP published as three articles in two Norwegian peer-reviewed journals (Andersen et al., 2010a; Andersen et al., 2010b; Andersen, 2011; Andersen et al., 2012). The t4 analysis is ready for publishing in winter/spring 2017.

The hypothesis has been that a universal preventive intervention in mental health, such as VIP, increases the level of knowledge, helping to change behavior and improving the mental health among adolescents. The research question was defined as:

"Do the adolescent self-reported mental health status and behavior in relation to seek help for mental health problems change through participation in a universal preventive intervention, which aims to increase the knowledge and the basis for decision regarding own or others' mental health problems?"

\section{Method}

The research was built as a quasi-experimental method with test and control groups with Solomon's design.

Figure 1. Solomons design

\begin{tabular}{|l|l|l|l|l|l|l|}
\hline & t 0 & & t 1 & t 2: 6 m & t 3: 12 m & t 4: 24 m \\
\hline Group 1 & Pretest & Intervention & Posttest 1 & Posttest 2 & Posttest 3 & Posttest 4 \\
\hline Group 2 & Pretest & & Posttest 1 & Posttest 2 & Posttest 3 & Posttest 4 \\
\hline Group 3 & & Intervention & Posttest 1 & Posttest 2 & Posttest 3 & Posttest 4 \\
\hline Group 4 & & & Posttest 1 & Posttest 2 & Posttest 3 & Posttest 4 \\
\hline
\end{tabular}


The key dependent variables in the project have been:

- self-reported mental health

- pupils' skills to recognize signs of mental disorders

- self-reported behavior in help-seeking

- students' knowledge level about mental health

I wanted to examine whether the intervention had an effect on these variables. Since I was interested in the whole range of indicators of mental health, and not primarily diagnosed disorder, I operationalized behavior and mental health through self-report. Nevertheless, I will emphasize that I am aware that there may be discrepancies between self-report and clinical ratings.

Changes are examined through self-reporting throughout repeated data collections among the same students. To assess the effects I have done comparisons of changes in sum scores or latent variables between the intervention and control group.

\section{Design}

For the assessment of mental health, I have used the self-report form of SDQNor (Heyerdahl, 2003; Van Roy, Groholt, Heyerdah, \& Clench-Aas, 2006; Ronning, Handegaard, Sourander, \& Morch, 2004; Goodman, Meltzer, \& Bailey, 1998). In the form, the various statements were answered as "not true," "somewhat true" or "certainly true" considered for the last six months. Each statement is scored the 0, 1 or 2.

Since anxiety represents a relatively stable 10-20\% of the clinical cases reported in Norway and SDQ-Nor not explicitly cover this area, I have chosen to add to the scale "anxiety symptoms", from the longitudinal TOPP study organized through The Norwegian Public Health Institute (Mathisen, 2013). Scoring 0-10 ( $\alpha=0.68$ ).

To assess changes in the other three outcome variables there were developed 7 indexes:

1. Familiarity with mental illness. Rate Scale: 0-12.

2. General knowledge about mental health. Rate Scale: 0-15.

3. Knowledge of different expression of diagnoses. Score Scale: 0-44.

4. Ability to connect symptoms to diagnosis. Rate Scale: 0-50.

5. Confidence in treatment. Rate Scale: 0-12.

6. Knowledge of support services related to mental health in general. Rate Scale: 0-30.

7. Knowledge of local community support services in mental health. Rate Range: 0-8.

For questions about knowledge, in cooperation with two professors at the University of Oslo it was decided in advance what the right answer was. Similarly, for attitudinal and behavioral questions determined what is the most desired attitude or behavior.

Information was collected through questionnaire prior to the intervention (t0) and 1 (t1), 6 (t2), 12 (t3) and 24 (t4) months after the intervention. At each data collection point, knowledge was measured as a percentage of the maximum score on the set of indexes, while the incidence of problems was measured by SDQ-Nor and scale for anxiety. 
To measure the dimensionality of the self developed indexes there are conducted analyzes of internal correlation and principal component analysis with Varimax rotation. The reliability is calculated using Cronbach Alpha/Kruder-Ricardsons (KR-20). The reliability of the scales and subscale has proven to be somewhat variable with alpha values between .437 and .972. For the analysis of the data sets collected we have used SPSS, version 14 .

The internal consistency of the scales has been calculated using Cronbach's alpha, while reliability of the scale and any individual items used have been estimated through a test-retest study. Effect sizes have been specified as Cohen's d-values (Cohen, 1988). Since the intervention largely has an intrinsic goal of changes in the psychosocial school environment, the allocation to groups is carried out from school and not classes. In all the statistical analyzes where there have been such opportunities, I have controlled for cluster effects without any finding of such (Shadish, Cook, \& Campbell, 2002; Cohen, West, \& Aiken, 2003; Goldstein, 1995).

\section{Sample and Response Rate}

The sample were a total of 880 pupils in Akershus county, where the intervention was implemented, compared with 811 students from Vestfold county who did not participate in this or other interventions on the completion date. Total average response rate from to to t3 was $79.3 \%$ for the intervention group and $76.7 \%$ for the control group. The individual questions were grouped, it was made basic additive sum scores, and changes were described using difference scores, total percent change, and Cohen $d$ with its belonging significance test.

Table 1 Number of pupils in populations and selection and number of responses at different times.

\begin{tabular}{|l|r|r|r|r|r|r|r|r|}
\hline & \multicolumn{4}{|c|}{ Akershus county } & \multicolumn{4}{|c|}{ Vestfold county } \\
\hline & t0 & \multicolumn{1}{|c|}{ t1 } & t2 & t3 & t0 & t1 & t2 & t3 \\
\hline $\begin{array}{l}\text { Number of pupils in first grade } \\
\text { in high schools }\end{array}$ & 7731 & & & & 3464 & & & \\
\hline Drawn for the evaluation project & 730 & 943 & & & 206 & 963 & & \\
\hline $\begin{array}{l}\text { Did not meet the criteria } \\
\text { for participation }\end{array}$ & 20 & 63 & 0 & & 12 & 152 & 0 & \\
\hline Included pupils & 710 & 880 & 880 & 880 & 194 & 811 & 811 & 811 \\
\hline Dropouts & 143 & 230 & 97 & 226 & 46 & 93 & 232 & 238 \\
\hline Usable responses & 567 & 650 & 783 & 654 & 148 & 718 & 579 & 573 \\
\hline Response rate in \% & 79,9 & 73,9 & 89 & 74,3 & 76,3 & 88,5 & 71,4 & 70,6 \\
\hline
\end{tabular}




\section{Results}

The main findings are that the program provides quite strong effects in the short-term when it comes to knowledge of mental health and support services. From to to t1, the intervention group significantly improved on the index "knowledge of mental disorders" (10.2\% improvement, Cohen's $d=0.58)$, "general knowledge about mental health" (4.4\% - 0.30), "ability to coupling of symptoms to diagnosis" (3.1\% - 0.34), "knowledge of the support services in mental health in general" $(11.6 \%-0.51)$ and "knowledge of local community support services in mental health" (11.3\% - 0.74). Knowledge about mental health seems to keep up pretty well in the first year after the intervention, while knowledge of the support services seems to be considerably forgotten. After six and twelve months we observed a small effect on help seeking.

Even more important, it seems to be a fairly surprising moderate to strong and significant beneficial effect on the prevalence of mental health problems. From time t1 to t3, we found significant differences between the intervention and control groups in change of the symptom level. On the SDQ-Nor total score I found a $16.5 \%$ relative reduction in mental health problems, $d=0.15$. In sub score "peers problems" (hereby also question about bullying) a relative reduction $31.8 \%, d=0.31$, and a $53.5 \%$ relative reduction anxiety problems, $d=0.37$. The program also seems to be a cost-effective intervention for schools.

Table 2 Effects on everyday life. Changes in mental health problems 12 months after. Subscale of peer problems and anxiety.

\begin{tabular}{|c|c|c|c|c|c|c|}
\hline Mental Health status (SDQ-Nor) & $\begin{array}{l}\text { Intervention } \\
\text { group } 1+3\end{array}$ & SD & $\mathrm{N}$ & $\begin{array}{c}\text { Control } \\
\text { group } 2+4\end{array}$ & SD & $\mathrm{N}$ \\
\hline \multicolumn{7}{|l|}{ SDQ-Nor total score $0-40$} \\
\hline t1, directly after the intervention & 9,22 & 5,8 & 276 & 8,88 & 5,1 & 249 \\
\hline t3, after12 m & 8,9 & 5,4 & 276 & 10,08 & 6,2 & 249 \\
\hline Total difference of change $0-40$ & \multicolumn{6}{|c|}{$16,50 \%$} \\
\hline Generalized effect, Cohens d & \multicolumn{6}{|c|}{0,15} \\
\hline Sig. t-test & \multicolumn{6}{|c|}{, $007 *$} \\
\hline \multicolumn{7}{|l|}{ Peer problems scale 0-10 } \\
\hline t1, directly after the intervention & 1,54 & 1,7 & 276 & 1,34 & 1,6 & 249 \\
\hline t3, after12 m & 1,34 & 1,6 & 276 & 1,63 & 1,9 & 249 \\
\hline Difference of change & \multicolumn{6}{|c|}{$31,80 \%$} \\
\hline Generalized effect, Cohens d & \multicolumn{6}{|c|}{0,31} \\
\hline Sig. t-test & \multicolumn{6}{|c|}{, $009 * *$} \\
\hline
\end{tabular}




\begin{tabular}{|c|c|c|c|c|c|c|}
\hline Mental Health status (SDQ-Nor) & $\begin{array}{l}\text { Intervention } \\
\text { group } 1+3\end{array}$ & SD & $\mathrm{N}$ & $\begin{array}{l}\text { Control } \\
\text { group } 2+4\end{array}$ & SD & $\mathrm{N}$ \\
\hline \multicolumn{7}{|l|}{ Anxiety scale 0-10 } \\
\hline t1, directly after the intervention & 1,27 & 1,8 & 269 & 1,01 & 1,5 & 240 \\
\hline t3, after12 m & 0,94 & 1,5 & 269 & 1,36 & 2 & 240 \\
\hline Difference of change & \multicolumn{6}{|c|}{$53,50 \%$} \\
\hline Generalized effect, Cohens d & \multicolumn{6}{|c|}{0,37} \\
\hline Sig. t-test & \multicolumn{6}{|c|}{, $001 * * *$} \\
\hline
\end{tabular}

\section{Conclusion}

The effects on mental health in the presented research project were most prominent in areas where improvement is largely dependent on the confidence and social contexts. The hypothesis is therefore that the psycho-educational effects of the intervention contribute, through changes in young people's insight/knowledge, which provide a higher degree of social support, increased knowledge for better decision making, reduction of stigma, lowering of the threshold for sharing problems and greater confidence in interpersonal processes, to improve the mental health of young people (Rüsch, EvansLacko, Henderson, Flach, \& Thornicroft, 2011).

Besides this research project, there is currently little research evidence on the effects of universal preventive mental health interventions in terms of changes in mental health. A search in the databases PubMed, MedLine, Psyclnfo, Embase, Cinahl, The Cochrane Library and Eric, conducted in November 2011, gave no hit on studies of universal preventive interventions in mental health and behavioral problems with power ratings/ effect assessment of mental health indicators using internationally validated instruments as SDQ or HSCL-10. Nevertheless we know that many young people have mental health problems or disorders.

Previous clinical studies have also shown that early intervention is of great importance with respect to prognosis. Early help from the health care system will provide young people with mental problems faster recovery and reduced risk of recurrent, severe illness periods, simultaneously the chance that the patient can live a normal life increases significantly. In order to get early help, however, the youth knowledge of the area is essential.

Founders: Regional Hospital Trust of South and East of Norway

Special thanks to: The Norwegian Public Health Institute, Division of Mental Health which where copartner and my daily workplace during the research project period from 2007 to 2010. 


\section{References}

Andersen, B. J. (2011). Effects of preventive mental health interventions in secondary Schools. PhD thesis. Psych Inst, UiO 12.2011. [online]. http://urn.nb.no/URN:NBN:no-30429.

Andersen B. J., Johansen, R., \& Nord, E. (2010). Teaching program in secondary schools about mental health: Effects on students help seeking and mental health. Nor Epidemiol, 20(1), 23-32.

Andersen B. J., Johansen, R., \& Nord, E. (2012). Preventive mental health intervention in secondary school: Learning outcome 6 and 12 months after. Journal of the Norwegian Psychological Association, 49(9), 854-860.

Andersen, B. J., \& Nord, E. (2010). Effects of programs in school for preventing mental problems. Nor Epidemiol, 20(1), 15-22.

Arnarson, E. O., \& Craighead, W. E. (2010). School based prevention programme may reduce depressive episodes in adolescents at risk. Evid Based Mental Health, 13(1), 15.

Aune, T., \& Stiles, T. C. (2009). Universal-Based Prevention of Syndromal and Subsyndromal Social Anxiety: A Randomized Controlled Study. Journal of Consulting and Clinical Psychology, 77(5), 867-879.

Cohen, J., Cohen, P., West, S. G., \& Aiken, L. S. (2003). Applied Multiple Regression/ Correlation Analysis for the behavioral Sciences, third edition. New Jersey: Lawrence Erlbaum Associates Publishers.

Cohen, J. (1988). Statistical power analysis for the behavioural sciences (2nd edition). Hillsdale, NJ: Erlbaum.

Cuijpers, P., van Straten, A., Smit, F., Mihalopoulos, C., \& Beekman, A. (2008). Preventing the Onset of Depressive Disorders: A Meta-Analytic Review of Psychological Interventions. The American Journal of Psychiatry, 165(10), 1272-1280.

Cuijpers, P., Munoz, R. F., Clarke, G. N., \& Lewinsohn, P. M. (2009). Psychoeducational treatment and prevention of depression: The "coping with depression" course thirty years later. Clin Psychol Rev 2009, 29(5), 449-458.

Durlak, J. A., \& Wells, A. M. (1997). Primary Prevention Mental Health Programs for Children and Adolescents: A Meta-Analytic Review. American Journal of Community Psychology, 25(2), 115-152.

Farrington, D. P., \& Ttofi, M. (2010). School-based programs to reduce bullying and victimization. Updated 8 March 2010. Campbell Syst Rev 2010; 2009 (6), 1-148. 
Gillham, J. E., Shatte, A. J., \& Freres, D. P. (2000). Preventing depression: a review of cognitive-behavioural and family interventions. Applied and Preventive Psychology, 9(2), 63-88.

Gladstone, T. R., \& Beardslee, W. R. (2009). The prevention of depression in children and adolescents: a review. Can J Psychiatry, 54(4), 212-221.

Goldstein, H. (1995). Multilevel statistical models (2nd ed.). London: Edward Arnold.

Goodman, R., Meltzer, H., \& Bailey, V. (1998). The Strengths and Difficulties Questionnaire: A pilot study on the validity of the self-report version. European Child and Adolescent Psychiatry, 7(3), 125-130. [online] http://www.sdqinfo.com/.

Greenberg, M. T., Domitrovich, C., \& Bumbarger, B. (2001). The prevention of mental disorders in school-aged children: Current state of the field. Prevention and Treatment, $4(1), 1-62$.

Greenberg, M. T., Weissberg, R. P., O’Brian, M. U., Zins, J. E., Fredricks, L., Resnik, H., \& Elias, M. J. (2003). Enhancing School-Based Prevention and Youth Development Through Coordinated Social, Emotional, and Academic Learning. American Psychologist, 58(6/7), 466-474.

Heyerdahl, S. (2003). SDQ - Strength and Difficulties Questionnaire: En orientering om et nytt spørreskjema for kartlegging av mental helse hos barn og unge, brukt i UNGHUBRO, OPPHED og TROFINN. Nor Epidemiol, 13(1), 127-135.

Horowitz, J. L., \& Garber, J. (2006). The prevention of depressive symptoms in children and adolescents: A meta-analytic review. J Consult Clin Psychol, 74(3), 401-415.

Jané-Llopis, E. (2005). From evidence to practice: Mental health promotion effectiveness. International Union for Health Promotion and Education (IUHPE): Promotion \& Education, Supplement 1, pp 21-27.

Lewinsohn, P. M., Rhode, P., Seeley, J. R., Klein, D. N., \& Gotlib, I. H. (2000). Natural Course of Adolescent Major Depressive Disorder in a Community Sample: Predictors of Recurrence in Young Adults. American Journal of Psychiatry, 157(10), 1584-1591.

Lipsey, M. W., \& Wilson, D. B. (1993). The efficacy of psychological, educational and behavioural treatment: Confirmation from meta-analysis. American Psychologist, 48(12), 1181-1209.

Mathisen, K. S. TOPP-study 2013. [online] http://www.fhi.no/studier/topp-studien/ sporreskjemaer.

Merry, S. N., \& Spence, S. H. (2007). Attempting to prevent depression in youth: A systematic review of the evidence. Early Interv Psychiatry, 1(2), 128-137. 
Merry, S. N., McDowell, H. H., Hetrick, S. E., Bir, J. J., \& Muller, N. (2009). Psychological and/or educational interventions for the prevention of depression in children and adolescents (Review). The Cochrane Collaboration. Published by Wiley \& Sons, Ltd. p. 2.

Neil, A. L., \& Christensen, H. (2009). Efficacy and effectiveness of school-based prevention and early intervention programs for anxiety. Clin Psychol, 29(3), 208-215.

Ronning, J. A., Handegaard, B. H., Sourander, A., \& Morch, W. T. (2004). The Strengths and Difficulties Self-Report Questionnaire as a screening instrument in Norwegian community samples. European Child and Adolescent Psychiatry, 13(2), 73-82.

Rüsch, N., Evans-Lacko, S. E., Henderson, C., Flach, C., \& Thornicroft, G. (2011). Knowledge and attitudes as predictors of intentions to seek help for and disclose a mental illness. Psychiatric Services, 62(6), 675-678.

Shadish, W. R., Cook, T. D., \& Campbell, D. T. (2002). Experimental and quasi-experimental designs for generalized causal inference. Boston/New York: Houghton Mifflin Company.

Spence, S. H., Sheffield, J. K., \& Donovan, C. L. (2005). Long-Term Outcome of a SchoolBased, Universal Approach to Prevention of Depression in Adolescents. Journal of Consulting and Clinical Psychology, 73(1), 160-167.

Tennant, R., Goens, C., Barlow, J., Day, C., \& Stewart-Brown, S. (2007). A systematic review of reviews of interventions to promote mental health and prevent mental health problems in children and young people. Journal of Public Mental Health, 6(1), 25-32.

The Norwegian Directorate of Health (NDH). Facts report on the causes of mental health problems and disorders, presented by a group of experts to The Norwegian Directorate of Health. 2000. I-0982B.

The Norwegian Directorate of Health (NDH). Mental health in school. 2013. [online] http://www.psykiskhelseiskolen.no/.

The Norwegian Knowledge Centre for the Health Services (NOKC). Health profile for kids and youth in Akershus, Report nr. 2. 2004.

Van Roy, B., Groholt, B., Heyerdahl, S., \& Clench-Aas, J. (2006). Self-reported strengths and difficulties in a large Norwegian population 10-19 years. Age and gender specific results of the extended SDQ-questionnaire. European Child and Adolescent Psychiatry, 15(4), 189-198.

W HT. The VIP-project. 2016. [online]. http://www.vestreviken.no/pasient_/laeringogmestring_/vipweb_/hvaervip_/Sider/Kontakt-oss.aspx (pages are under reconstruction, info in English take contact through postvip@vestreviken.no). 
Weist, M. D., \& Albus, K. E. (2004). Expanded School Mental Health. Behaviour Modification, 28(4), 463-616.

Weisz, J. R., Sandler, I. N., Durlak, J. A., \& Anton, B.S. (2005). Promoting and Protecting Youth Mental Health Through Evidence-Based Prevention and Treatment. American Psychologist, 60(6), 628-648.

\section{Author}

Bror Just Andersen, PhD Psychol

Baerum DPC, Division of Mental Health and Addiction

Vestre Viken HT, Norway

broand@vestreviken.no 